been under the treatment of sulfasalazine and he has remained asymptomatic.

Conclusion Calciphylaxis may appear without renal failure and hyperparathyroidism. Long-term steroid using in RA patients may lead to calciphylaxis. Acquired protein $S$ deficiency may contribute to this process.

\section{AB0094 PREVALENCE OF TWIN BIRTHS IN BEHÇET'S DISEASE (BD)}

S Masatlyoðlu, F Göðüp, B Yýldýrým, R Tunç, I Fresko, H Yazýcý. Rheumatology, Cerrahpapa Medical Faculty, Istanbul, Turkey

\subsection{6/annrheumdis-2001.201}

\section{Background}

Objectives Studies of twins in BD have been few. ${ }^{1,2}$ Our clinical impression has been that patients with BD had a paucity of twin siblings. We studied the frequency of twin siblings among the BD patients in a controlled protocol.

Methods 1277 patients ( 773 males and 504 females with a mean age of $34.20 \pm 9.59$ years) attending a dedicated BD outpatient clinic were asked whether they had a twin sibling, living or dead. Inquiry into monozigosity was made by asking whether this twin (s) looked exactly like the proband as 'two peas in a pod'. ${ }^{3}$ As controls the same information was sought among i. a group of patients with either rheumatoid arthritis (RA) or systemic lupus (SLE), composed of 180 patients with RA -150 males and 30 females with a mean age of $49.08 \pm 14.05$ yearsand 79 patients with SLE - 64 females and 15 males with a mean age of $34.80 \pm 12.33$ years- all attending a rheumatology outpatient clinic; and ii. among 7761 first year university students 3848 males and 3913 females with a mean age of $18.55 \pm 1.38$ years- during their university registration. Chi-square test $\left(2_{\mathrm{df}}\right)$ was used to compare the findings between the three groups.

Results Among the 7761 university students, 120 twins (1.5\%) were identified. 92 were dizygotic (1.2\%) and $28(0.38 \%)$ monozygotic. Among the 259 patients with connective tissue disease there were $7(2.7 \%)$, all dizygotic twins. Two twins belonged to the SLE and 5 to the RA patients. Among the 1277 patients with BD there were 10 twins $\left(0.08 \% ; \mathrm{x}^{2}{ }_{2 \mathrm{df}}=7.17, \mathrm{p}\right.$ $=0.03)$. Eight were dizygotic and $2(0.15 \% ; \mathrm{p}>0.12)$ were monozygotic. The monozygotic twins were discordant for BD in either case.

Conclusion The frequency of twin births among our controls was similar to that reported in general for twin-births. ${ }^{4}$ The rather marked decrease, 19 fold when compared to the group of university students and 34 fold when compared to the group of patients with RA or SLE, in the twin frequency among the BD patients could be due to the presence of in utero factors operative in the mothers of patients with $\mathrm{BD}$, unfavourably affecting the successful initiation and/or completion of a twin pregnancy.

\section{REFERENCES}

1 Hamuryudan V, et al. Arhtritis Rheum. 1991;34(8):1071-2

2 Gül A, et al. Br J Rheumatol. 1997;36(8):922-7

3 Cederlöf R, et al. Arch Environ Health 1967:14:401

4 Mac Gillivray I. Semin Perinatal. 1986;10(1):4-8

\section{AB0095 INTRAVENOUS IMMUNOGLOBULIN IN LIMITED POLYARTERITIS NODOSA}

${ }^{1}$ A Balbir-Gurman, ${ }^{1} D$ Schapira, ${ }^{2} B$ Smolin, ${ }^{2} E$ Volfovitz, ${ }^{1} A M$ Nahir. ${ }^{1} B$. Shine Department of Rheumatology; 'Department of Medicine " $D$ ", Rambam Medical Center, Faculty of Medicine, Haifa, Israel

\subsection{6/annrheumdis-2001.202}

Background Polyarteritis nodosa (PAN) is severe systemic vasculitis that may affect almost all systems. Rarely isolated organ involvement occurs. These cases generally have more benign course and respond well to high dose of steroids. The addition of cytotoxic drugs is controversial. PAN limited to calf muscles is extremely uncommon. Painful tenderness and swelling of dorsal calf muscles, mild fever and general signs of inflammation in blood tests are the only features of this form of vasculitis. ANCA is not obligatory positive. Muscle biopsy is the only way to make the diagnosis.

Objectives

Methods

Results

\begin{tabular}{lll} 
Abstract AB0095 Table 1 & & \\
\hline & Case 1 & Case 2 \\
& $24 \mathrm{M}$ & $\mathbf{2 7} \mathrm{F}$ \\
\hline Calve's pain/tenderness & Yes/Yes & Yes/Yes \\
Walking difficulties & Yes & Yes \\
Fever & 37.4 & 37.2 \\
Regional muscle weakness & Yes & No \\
Haemoglobin (g/dl) & 10.8 & 11.4 \\
ESR (mm/1 h) & 85 & 72 \\
ANCA & pANCA positive & Negative \\
Prednisone 0.5 mg/d and IVIG 25 g/d for 5 & 10 weeks off & 8 weeks off \\
days & steroids & steroids
\end{tabular}

ESR-Erythrocyte Sedimentation Rate, ANCA-Antineutrophil Cytoplasmic Antigen, pANCAperinuclear ANCA, IVIG-Intravenous Immunoglobulin.

Conclusion The two herein reported cases (Table 1) of biopsy proven PAN of the calve show that the addition of single course of intravenous immunoglobulin to steroid treatment yielded rapid and stable clinical and laboratory remission with low doses of steroids from the beginning and rapid tapering off.

\section{AB0096 TWO CASES OF BEHCET'S DISEASE WITH ULCERS ON GLANS PENIS}

${ }^{1} \mathrm{~T}$ Pirildar, ${ }^{1} \mathrm{~T}$ Turk, ${ }^{1} \mathrm{E}$ Tunc, ${ }^{1} \mathrm{~V}$ Inal, ${ }^{1} \mathrm{G}$ Keser, ${ }^{2} \mathrm{~A}$ Varol, ${ }^{1} \mathrm{E}$ Doganavsargil, ${ }^{1} \mathrm{G}$ Gumusdis. ${ }^{1}$ Rheumatology; ${ }^{2}$ Dermatology, Ege University, Izmir, Turkey

10.1136/annrheumdis-2001.203

Background Behcet's Disease (BD), when first described in 1937, was consisted of three symptoms; recurrent oral, genital ulcerations and iridocyclitis. Today, it is known that BD is a multisystemic chronic vasculitic disorder which may involve both arteries and veins of all sizes. Although painful scrotal ulcers healing with scar formation are among the main clinical findings of $\mathrm{BD}$, ulceration of glans penis is unusual.

Objectives

Methods

Results We present two cases of BD with ulcers on glans penis. The first case is a 46-year-old man who presented with 
ulceration involving glans penis and diagnosed as BD after investigations. The second case was a 23-year-old man with established $\mathrm{BD}$ who later developed ulcers on glans penis during the course of the disease. In our 113 patients with BD, 102 patients (90.2\%) had genital ulcers. Among these 102 patients having genital ulcers, only these two cases $(1.9 \%)$ had ulcers localised on the glans penis.

Conclusion In conclusion, the possibility of BD should also be considered in patients presenting with genital ulcer (s) with atypical localizations, such as glans penis, particularly in countries with a high prevalance of this disease.

\section{AB0097 EXTRA PYRAMIDAL SYNDROME AS A MANIFESTATION OF TEMPORAL ARTERITIS}

DG Michas, A Papadopoulos, E Sarra, M Deutsch, S Lionaki, P Kotsakis. Internal Medicine, General Hospital of Patissia, Athens, Greece

\subsection{6/annrheumdis-2001.204}

Background Temporal arteritis as a form of vasculitis can sometimes manifest itself be with neurological complications.

Cases with symptoms of extra pyramidal system are rarely reported in bibliography.

A case of a patient with temporal arteritis who presented lethargic syndrome followed by Parkinson disease is reported.

Objectives Case report.A woman 80 years old was firstly admitted to our hospital with enlarged neck lymph nodes and fever. A lymph node biopsy indicated TBC. She was supplied with anti TBC treatment and significantly improved. Two months later she was admitted again with symptoms of rigour, neck stiffness and lethargy. Subarachnoid haemorrhage or meningitis was suspected. Brain CT scan and lumbar puncture were negative. She was supplied with corticosteroid treatment in large doses and the next day all the symptoms disappeared. On leaving hospital she was advised to continue the corticosteroids and gradually stop them. A month later and 10 days after finishing her therapy, she was again admitted with high fever, headache and extrapyramidal syndrome with hand and tongue tremor, stiffness of the musculature, hypokinesia and immobile facial expression. Physical examination indicated painful bilateral temporal arteries. Left temporal artery biopsy indicated giant cell arteritis. She was treated again with corticosteroids only and the signs and symptoms of temporal arteritis and extapyramidal syndrome disappeared. Patient is examined energy six months and her health has continuously been good.

Methods

Results

Conclusion Temporal arteritis in rare forms of the disease is likely to manifest itself with parkinsonian syndrome. Corticosteroidal treatment is enough to improve the disease without supplement any special antiparkinsonian treatment.

\section{AB0098 GALLIUM SCANS AND POLYMIALGIA RHEUMATICA}

M Castellanos Duarte, N Navarro, MC Garcia, C Galisteo, M Sanmartí, MP Lisbona, C Alegre. Rheumatology, Hospital Malalties Reumatiques, Barcelona, Spain

\subsection{6/annrheumdis-2001.205}

\section{Background}

Objectives We evaluated utility of gallium scintigraphy to the diagnose of polymialgia rheumatica (RPM).
Methods Gallium scans were performed in 7 patients (5 women, 2 men) diagnosed RPM according to American College of Rheumatology (ACR) criteria. Mean age were 65 years. Temporal pulses were palpable in all of them. All were taking corticosteroids. None of patients had any other known or clinically inflammatory or granulomatous disease.

Scintigraphy with gallium is non-invasive diacritic procedure that could help to locate the vasculitic process. All scintigraphies were performed in the Nuclear Medicine Unit of Clinica Platon. Results Scintrigraphy of temporal region don't show an uptake of gallium radionuclide in this localizatión.

Conclusion Gallium scans confirmed that patients were correctly diagnosed of RPM, because we didn't see an uptake of studied area, like in temporal arteritis due to the granulomatous vasculitic process.

\section{AB0099 ADULT ONSET STILL'S DISEASE REVELALED BY PERICARDIAL TAMPONADE AND MYOCARDITIS}

S Aloui, H Ben Fredj, I Bouajina, M Khelifa, F Bahri, MH Abdessalem, T Chekir. Rheumatology, Farhat Hached Hospital, Sousse, Tunisia

\subsection{6/annrheumdis-2001.206}

Background Pericardial tamponade and myocarditis are very seldom complication of adult onset Still's disease and exceptionally revealed the disease. A18-year- old man was hospitalised for fever, polyartharalgia, dyspnea and thoracic pain. Chest radiograph demonstrated large cardiac sillouette. The electrocardiogram showed tachycardia and non specific diffuse ST-T changes.

Echocardiography revealed a mild alteration of left ventricular function and circumferential pericardial effusion with diastolic collapse. A pericardiocentesis yielded $300 \mathrm{ml}$ of sersanguinos fluid. The white blood cell count was 41200 with $96 \%$ neutophils. An extensive evaluation for infection was unrevealing and tests for antinuclear factors and rheumtoid factor were negative. Still's disease was diagnosed. The patient was treated with prednisone $1 \mathrm{mg} / \mathrm{kg} /$ day and rapidly improved.

Objectives

Methods

Results

Conclusion

\section{AB0100 SYSTEMIC MANIFESTATION OF BEHCET ADAMANTIADES SYNDROME}

DV Mitrovic, L Pavlica, BC Glisic, MR Petronijevic, G Pavlovic. Clinics of Rheumatology, Military Medical Academy, Belgrade, Yugoslavia

\subsection{6/annrheumdis-2001.207}

Background After the disease was firstly described it was beleived that this syndrome consisted of three symptoms ? orogenital ulcerations and inflammatory disease of eyes. In last several decades numerous facts indicated that we have deall systemic vasculitis, that induced multiorgan manifestations.

Objectives The aim of this study is: a) to analyse 64 patients and find the spectrum of systemic manifestations of the disease, b) to show therapeutic approach in acute phase of the disease.

Methods All patients fulfilled diagnostic criteria for the diagnosis of Behcet-Adamantiades syndrome.

Results Out of systemic manifestations the most common was the involvement of locomotoric system ? arthritis 38 (59\%), 